\title{
Importance of Blood Glucose Monitoring to Achieve Short- and Long-Term Glycemic Control
}

\author{
Lenore Coleman and Barbara Livermore
}

\begin{abstract}
OBJECTIVE: To review the importance of short- and longterm glucose monitoring in people with diabetes, emphasizing the relationship between elevated fasting and postprandial glucose levels and their association with hemoglobin A1C (HbA1C)

DESIGN: Literature review

RESULTS: Numerous epidemiologic and interventional studies have demonstrated that lowering blood glucose to normal or near-normal levels for several years prevents the onset and delays the progression of microvascular complications including retinopathy, nephropathy, and neuropathy. Based on a substantial amount of data, the American Diabetes Association recommends that treatment of all individuals with diabetes be aimed at lowering blood glucose to normal or near-normal levels.
\end{abstract}

CONCLUSIONS: Frequent self-monitoring of blood glucose (SMBG), if used properly, can be effective at improv- ing glycemic control on a day-to-day basis. SMBG should be done daily and should include measurement of both fasting and postprandial blood glucose levels. Routine measurements of $\mathrm{HbA1C}$ are used for measuring longterm control (90 to 120 days) and highly correlate with the incidence and progression of diabetic complications. This makes $\mathrm{HbA} 1 \mathrm{C}$ a valuable clinical tool for both assessing long-term glycemia and predicting risk for the development of chronic complications. Achieving glycemic control through an interdisciplinary, comprehensive diabetes care program is beneficial to the patient and may be costeffective within an integrated health care system. Diabetes should be identified as a target for disease state management programs

KEYWORDS: Diabetes, Glucose monitoring, Student education, School of pharmacy

J Managed Care Pharm 1999: 543-547
LENORE T. COIEMAN, PHARM.D., C.D.E., FA.S.H.P., is a Clinical Science Specialist for the Bayer Corporation, Altadena, CA, and an Adjunct Assistant Professor of Clinical Pharmacy at the University of Southern California, School of Pharmacy; Los Angeles, CA. BARBARA M. LIVERMORE, M.D., is Chief of Endocrinology, Kaiser Permanente Medical Group, Inc., Sacramento, CA and Chairperson, Professional Education Committee, California Diabetes Coalition, Sacramento, CA.

Copyright $(1999$ Academy of Managed Care Pharmacy, Inc. All rights reserved
$\mathrm{P}$ oint-of-care testing and self-monitoring of blood glucose (SMBG) have dramatically enhanced the ability of both patients and clinicians to improve glycemic control. Results of blood glucose testing are used to assess the efficacy of medication therapy, enforce behavior modification in medical nutrition therapy and exercise, and facilitate changes in lifestyle. SMBG also can minimize chronic hyperglycemia, re-duce the frequency and magnitude of hyperglycemic excursions, and alert patients to the signs of impending diabetic ketoacidosis or hypoglycemia. The importance of achieving target blood glu-cose values to minimize or prevent microvascular complications has led to more patients performing dayto-day testing. This paper reviews the importance of shortand long-term glucose monitoring in people with diabetes, emphasizing the relationship between elevated fasting and postprandial glucose levels and their association with hemoglobin Alc (HbAlc).

\section{TARGETING BLOOD GLUCOSE LEVELS TO ACHIEVE GLYCEMIC CONTROL}

Due to an overwhelming amount of epidemiologic and interventional data, the American Diabetes Association (ADA) recommends that treatment of individuals with diabetes aim at lowering blood glucose to normal or near-normal levels (see Table 1), and advises that most patients on insulin should follow intensive treatment programs that include frequent 
Table 1. Target Levels of Glucose Control

\begin{tabular}{l|c|c}
\hline Biochemical Measurement & Normal & Acceptable \\
\hline Preprandial glucose (mg/dL) & $<115$ & $70-120^{*}$ \\
\hline Bedtime glucose (mg/dL) & $<120$ & $100-140$ \\
\hline Postprandial (90 min) glucose (mg/dL) & $<140$ & $<180^{*}$ \\
\hline Glycated hemoglobin (\%) & $<6$ & $<7$ \\
\hline
\end{tabular}

*DCCT goal for intensive therapy; †Normal reference range: $4 \%-6 \%$

SMBG ${ }^{1,2}$ Further, these guidelines state that patients with Type 1 diabetes should use premeal and bedtime glucose levels of 70 to $120 \mathrm{mg} / \mathrm{dL}(4.44-6.67 \mathrm{mmol} / \mathrm{L})$ and 100 to $140 \mathrm{mg} / \mathrm{dL}$ $(5.50-7.78 \mathrm{mmol} / \mathrm{L})$, respectively, as targets. To achieve these levels, comprehensive treatment programs that include intensified insulin therapy, nutritional counseling, behavior modification, measurements of glycoslyated hemoglobin, and SMBG have been devised.

The control of postprandial blood glucose levels is also important in the overall management of persons with diabetes The Diabetes Control and Complication Trial Research Group (DCCT) published data on the relationship between the glycosylated hemoglobin value and the risk of complications. The DCCT concluded that mean HbAlc may not express the degree of hyperglycemia and that the risk of complications may depend on the extent of postprandial glucose excursions.

Postprandial glucose excursions are synonymous with the acute rise of blood glucose that occurs after a meal. The report of the six-year United Kingdom Prospective Diabetes Study (UKPDS) showed that "despite continuing dietary advice, and increasing doses of sulfonylureas, metformin, and insulin, by six years after the diagnosis of diabetes, $53 \%, 59 \%$, and $47 \%$ respectively of patients in the intensive group had fasting plasma glucose (FPG) levels above $140 \mathrm{mg} / \mathrm{dL}$." Four to six years after initiating therapy with metformin, sulfonlyureas, and insulin, $\mathrm{HbAlc}$ levels generally returned to the higher values that existed before therapy. ${ }^{4}$ These increased HbAlc levels may be attributable to increasing postprandial glucose excursions.

\section{IMPROVED GLYCEMIC CONTROL IN TYPE 1 AND TYPE 2 DIABETES}

In 1993, the results of the DCCT study in 1,440 patients with Type 1 diabetes demonstrated that intensive therapy over a nine-year period effectively prevented the onset and delayed the progression of diabetic retinopathy, nephropathy, and neuropathy relative to conventionally treated patients. ${ }^{5}$ Although the DCCT was conducted in patients with Type 1 diabetes, other studies have provided evidence that reductions in hyperglycemia to DCCT-recommended levels $(\mathrm{HbAlc}=7.2 \%)$ will produce favorable effects on microvascular and macrovascular disease in patients with Type 2 diabetes. ${ }^{6.8}$ In the DCCT, one of the drawbacks to intensive insulin therapy was a threefold increase in hypoglycemic reactions.

Recent data from Vijan et al. demonstrated that reducing $\mathrm{HbAlc}$ from $9 \%$ to $7 \%$ results in a $2.3 \%$ decrease in lifetime risk for blindness due to retinopathy. ${ }^{9}$ Eastman et al. analyzed the health benefits and cost effectiveness of treating Type 2 diabetes with the goal of normoglycemia, and showed that comprehensive treatment that maintains an $\mathrm{HbAlc}$ of $7.2 \%$ is predicted to reduce the cumulative incidence of blindness, end-stage renal disease, and lower extremity amputation by $72 \%, 87 \%$, and $67 \%$ respectively. ${ }^{10}$

The UKPDS was a multicenter randomized controlled trial comparing different therapies in newly diagnosed Type 2 diabetic patients that lasted for 20 years. ${ }^{11}$ The UKPDS was designed to determine if intensive therapy to achieve near-normal glycemia would reduce microvascular and macrovascular complications in Type 2 patients. The study evaluated 3,867 newly diagnosed Type 2 patients over a 10-year period. It compared conventional therapy (diet plus medications to achieve an FPG of $15 \mathrm{mmol} / \mathrm{L}$ ) to intensive therapy (diet plus medications to achieve an $\mathrm{FPG}$ of $6 \mathrm{mmol} / \mathrm{L}$ ).

The medications used in the study were chlorpropamide $500 \mathrm{mg} /$ day, glibenclàmide $2.5-20 \mathrm{mg} /$ day, glipizide $2.5-40$ $\mathrm{mg} /$ day, insulin therapy (both intermediate and short-acting), or metformin 500-2550 mg/day. Results showed that the intensive therapy group was able to achieve and maintain a $0.9 \%$ reduction in $\mathrm{HbAlc}$ ( $11 \%$ reduction). This reduction led to a $12 \%$ lower risk of any diabetes-related endpoint, $10 \%$ lower risk for any diabetes-related death, and $6 \%$ lower risk for all-cause mortality. Intensive therapy also yielded a $25 \%$ risk reduction in microvascular endpoints. All medications were equally effective. Patients in the intensive therapy group had more hypoglycemic episodes and gained significantly more weight.

Before the DCCT and:UKPDS studies were completed, the results of animal and human studies predicted a strong relationship between the duration and severity of hyperglycemia and the occurrence and progression of diabetic complications. Hyperglycemia has been shown to cause comparable morphologic abnormalities in retinopathy, ${ }^{12-14}$ nephropathy, ${ }^{15-17}$ and neuropathy ${ }^{19}$ in Type 1 and Type 2 patients. In one study of patients with incipient diabetic nephropathy, two years of strict metabolic control prevented the development of clinical nephropathy. ${ }^{18}$ Strict control of blood glucose as assessed by short- and longterm measures has been found to be critically important during pregnancy and has a positive effect on fetal outcome..$^{20-23}$

\section{BENEFIT OF MONITORING BLOOD GLUCOSE}

Multiple studies have been conducted evaluating the impact of SMBG on glycemic control. Most of the studies evaluated SMBG within the context of a comprehensive diabetes care program that included nutrition and exercise counseling. Dudl et al. evaluated 29 Type 2 diabetics over 12 months. ${ }^{2+}$ These 
patients participated in a comprehensive program that included dietary intervention, education, routine follow-up, and SMBG seven times per day. Twenty-seven of the 29 patients had an improvement in HbAlc from a mean of $11.4 \%$ to $8.7 \%$. Routine clinic visits, emergency room visits, hospital days, and telephone calls decreased by $79 \%, 54 \%, 87 \%$, and $70 \%$ respectively. This decrease in utilization of services equated to an estimated savings of $\$ 364$ per patient in the first year. ${ }^{24}$

A recent criteria-based literature review from 1976-1996 found only four studies that met their quality criteria. ${ }^{25}$ Rutten et al. conducted one of the four studies that demonstrated a significantly positive result with SMBG.$^{26}$ Rutten conducted a randomized control trial in 100 patients to determine the efficacy of SMBG, using HbAlc and weight as efficacy measures. The mean change in $\mathrm{HbAlc}$ was $-0.4 \%$ in the SMBG group versus $+0.5 \%$ in the control group $(p<0.05)$. The patients in the SMBG group lost weight, whereas the control group gained weight (nonsignificant). At this point compelling data exists that clearly demonstrates the need to incorporate SMBG as an integral part of the comprehensive care of the persons with diabetes. This fact needs to factor into the decision-making process related to hypoglycemia therapy, insulin or oral antidiabetic medication adjustment, nutritional instruction, exercise, and assessment of complications.

\section{SHORT-TERM BLOOD GLUCOSE MONITORING}

Short-term monitoring of blood glucose is used in the management of patients with diabetes either for a specific purpose or for a discrete period of time, as in the management of patients with impaired glucose tolerance (IGT) or gestational diabetes.

IGT refers to a metabolic stage between normal glucose hemostasis and diabetes. Many patients with IGT have normal fasting blood glucose values and may have normal or nearnormal HbAlc levels. If these patients become ill and require hospitalization, they will require bedside monitoring of their blood glucose. Insulin may be required during the hospitalization and is usually given based on fixed-dose algorithms that are linked to monitoring of capillary blood glucose levels.

Gestational diabetes mellitus (GDM) is defined as any degree of glucose intolerance with onset or first recognition during pregnancy. In the majority of cases of GDM, glucose regulation will return to normal after delivery. Deterioration of glucose tolerance occurs normally during the third trimester. Women with gestational diabetes require short-term use of SMBG. Keeping blood glucose levels as close to normal as possible is very important for these patients. Kitzmiller et al. evaluated preconception care of 84 GDM patients versus postconception care for 110 GDM patients and its effects on congenital anomalies. ${ }^{27}$ All patients self-monitored their blood glucose at least four times a day, during fasting and one hour after meals. Goals for preprandial levels were $60-100 \mathrm{mg} / \mathrm{dL}$; onehour postprandial goal was $100-140 \mathrm{mg} / \mathrm{dL}$. Results from the study showed that the rate of congenital anomalies was reduced when intensive management of blood glucose was instituted before or early in pregnancy.

Adjusting therapy based on postprandial glucose monitoring has been shown to be more effective than basing therapy on preprandial monitoring when the goal is improved glycemic control. De Veciana et al. randomly assigned 66 GDM patients to adjust their insulin based on preprandial or postprandial levels. ${ }^{28}$ The target for preprandial levels was $60-105$ $\mathrm{mg} / \mathrm{dL}$ and postprandial levels was $<140 \mathrm{mg} / \mathrm{dL}$. When the postprandial or premeal glucose was evaluated to determine treatment effects, greater reduction in glycosylated hemoglobin occurred when the postprandial value was used $(-3.0 \pm 2.2 \%$ versus $0.6 \pm 1.6 \%, \mathrm{p}<0.001$ ). The patients in the postprandial monitoring group had a $70 \%$ reduction in all the complications of gestational diabetes. The study concluded that adjusting insulin treatment based on postprandial rather than premeal monitoring of blood glucose may be more effective in improving glycemic control in GDM patients and may decrease the risk of neonatal hypoglycemia, macrosomia, and cesarean delivery.

Avignon et al. also demonstrated the importance of postprandial glucose levels. ${ }^{29}$ This study evaluated the relative value of plasma glucose measurements at different times of the day in comparison with HbAlc measurements in 66 Type 2 patients and found that post-lunch (two hours) and extended post-lunch (five hours) measurements are better predictors of glycemic control than fasting plasma glucose.

Short-term monitoring of blood glucose can be achieved by measuring the glycosylation of serum proteins that occurs during periods of hyperglycemia. The measurement of serum. fructosamine (a glycosylated protein) has been used to monitor short-term control in patients with diabetes. Measurement of fructosamine levels reflects average glucose control for two to three weeks and therefore allows earlier identification of adverse glycemic events and fosters earlier therapeutic intervention. HbAlc is measured as a percentage of glycosylated hemoglobin relative to total hemoglobin, whereas fructosamine is measured as micromoles of fructosamine per liter of blood (umol/L). The advantage of fructosamine is that the testing is standardized from one laboratory to another and is potentially more accurate in patients with anemia. Studies in the elderly and in diabetic outpatients have found fructosamine to have clinical validity as a short-term marker of glycemic control. ${ }^{30,31}$

\section{FREQUENCY OF TESTING}

The ADA recommends that efforts be made to substantially increase appropriate use of SMBG. According to a national survey conducted by Harris et al., $67 \%$ of people with diabetes have never checked their blood glucose. ${ }^{32}$ Forty percent of Type 1 and $26 \%$ of Type 2 patients monitor at least once a day.

All treatment programs should encourage SMBG for routine daily monitoring in Type 1 patients. Frequency and timing should be dictated by the needs and goals of the individual patients, but most Type 1 patients should monitor their plasma glucose 
before breakfast, one to two hours after each meal, before and after exercise, and at bedtime on a daily basis. For Type 2 patients the ADA recommends "a sufficient number of tests should be performed to reach glucose goals." ${ }^{33}$ Generally, Type 2 patients should conduct at least two tests per day at various times throughout the day, before and after meals. Daily SMBG is especially important for Type 2. patients treated with insulin or sulfonylureas to monitor for and prevent asymptomatic hypoglycemia.

In the DCCT, the glycemic goals for intensive therapy included premeal, 90-minute post-meal, and weekly 3 a.m. blood glucose levels of 70 to $120 \mathrm{mg} / \mathrm{dL}(3.9-6.7 \mathrm{mmol} / \mathrm{L}),<180 \mathrm{mg} / \mathrm{dL}$ $(10 \mathrm{mmol} / \mathrm{L})$, and $>65 \mathrm{mg} / \mathrm{dL}$ ( $3.61 \mathrm{mmol} / \mathrm{L})$, respectively. The DCCT study results also suggested that these targets be further adjusted in patients with a history of recurrent severe hypoglycemia or in those with hypoglycemia unawareness. ${ }^{1.2}$

\section{LONG-TERM GLUCOSE MONITORING}

Fasting or postprandial blood glucose testing is useful for dayto-day monitoring of glycemic control. However, these tests cannot provide an accurate measure of glycemia over an extended period of time. Measurement of glycosylated proteins is a means of determining average glycemia over a period of weeks to months, thereby complementing day-to-day testing. $\mathrm{HbAlc}$, one of several glycosylated hemoglobins that reflect glycemic status, has been studied extensively. HbAlc is the stable product of nonenzymatic glycosylation of the eight chain of hemoglobin by plasma glucose; it is found at concentrations that increase with increasing plasma glucose levels.

Because erythrocytes are freely permeable to glucose, the level of glycosylated hemoglobin in a blood sample provides an estimate of the degree of glycemia over the previous 90120 days, which is the average erythrocyte life span. ${ }^{2}$ Measurement of glycosylated hemoglobin has been available since the late 1970s. It is recommended for routine testing of long-term glycemic control in all patients with diabetes, 1) to document the degree of glycemic control at the initial assessment; then 2) as part of continuing care, since it can quantify average glycemia over the previous 90-120 days. 'Interpretation of $\mathrm{HbAlc}$ test results requires an understanding of the relationship between the test results and average blood glucose, the kinetics of HbAlc formation, specific assay limitations, and patient factors that can affect the results.

In light of the DCCT and UKPDS results, $\mathrm{HbAlc}$ testing is recommended for use in routine monitoring of all patients with diabetes. ${ }^{1,2}$ These studies showed that HbAlc levels can be used clinically to assess long-term glycemic status and to predict risk for development of the chronic complications of diabetes. ${ }^{15,12}$ Some studies suggest that treatment strategies utilizing HbAlc testing can improve, per se, glycemia in Type 1 diabetes. ${ }^{2,34}$

Glycosylated hemoglobin values in diabetic patients represent a continuum, ranging from normal to elevations of twoto three-fold, making it difficult to relate the HbAlc test result to average blood glucose values; however, general guidelines can be suggested. ${ }^{34}$ Data analysis from the DCCT has revealed that when HbAlc and 24-hour seven-point blood glucose profiles were measured quarterly for one year in 278 subjects, a linear relationship existed between average glycemia and glycosylated hemoglobin level $(r=0.80, p<0.0001)$. Approximately each $1 \%$ increase in glycosylated hemoglobin was related to a $30 \mathrm{mg} / \mathrm{dL}(1.99 \mathrm{mmol} / \mathrm{L})$ increase in average blood glucose. ${ }^{5.34}$ In addition, if one multiplied the HbAlc by approximately 23 , the resulting number would represent the average blood glucose, assuming that the usual range for $\mathrm{HbAlc}$ is $4 \%-6 \%$.

\section{COST OF COMPREHENSIVE DIABETES CARE IN A MANAGED CARE SETTING}

Many integrated health care systems are looking at the cost of comprehensive care of their patients with diabetes. Gilmer et al. examined the relationship between glycemic control and medical care charges for 3,017 adults with diabetes enrolled in a large health maintenance organization over a four-year period, and found that for a person with an HbAlc value of $6 \%$, successive $1 \%$ increases in $\mathrm{HbAlc}$ resulted in cumulative increases in medical charges of approximately $4 \%, 10 \%, 20 \%$, and $30 \% .{ }^{35}$ These researchers concluded that for economic as well as clinical reasons, lowering $\mathrm{HbAlc}$ when it is $>8 \%$ is beneficial.

Selby et al. estimated the excess costs of medical care of patients with diabetes in a managed care population to determine the proportion of costs spent on treating the complications of diabetes. ${ }^{36}$ This study compared 1994 medical costs of medical care among the 85,209 members of the diabetes registry of Kaiser Permanente Northern California, and in 85,209 age- and sex-matched nondiabetic control subjects.

Expenditures for members with diabetes were 2.4 times those for matched controls $(\$ 3,494)$. Nearly $38 \%$ of the excess was spent treating the long-term complications of diabetes, predominantly coronary heart disease and end-stage renal disease. The researchers concluded that disease state management programs that aim to prevent complications could potentially lead to cost savings. ${ }^{36}$

Eastman et al. analyzed the health benefits and cost effectiveness of treating Type 2 diabetes with the goal of normoglycemia, using an incidence-based simulation model of noninsulindependent diabetes mellitus and estimated treatment costs from national survey data and clinical trials. ${ }^{10}$ An estimated incremental cost per Quality Adjusted Life Years (QALY) was calculated comparing comprehensive to standard treatment of Type 2 diabetes. QALY is a single comprehensive indicator of health improvement resulting from a medical intervention within an individual. Technologies or interventions that cost less than $\$ 20,000 /$ QALY are considered an acceptable expenditure of health care system resources. ${ }^{37.38}$ The results of this study demonstrated that comprehensive treatment of Type 2 diabetes that maintains an $\mathrm{HbAlc}$ value of $7.2 \%$ reduces the incidence of blindness, end-stage renal disease, and lower extremity amputations. Life expectancy increased by 1.39 years and the estimated incremental cost/QALY gained is $\$ 16,002 .^{10}$ 


\section{SUMMARY AND CONCLUSIONS}

Intensive treatment of diabetes mellitus requires effective blood glucose monitoring methods, including SMBG. Due to wide fluctuations in blood glucose levels, the frequent practice of periodic monitoring of fasting glucose levels has been questioned, and there is evidence that postprandial glucose levels may provide a better measure of short-term glycemic control.

The most comprehensive method of monitoring glycemic control over an extended period of time is the assessment of $\mathrm{HbAlc}$, which is formed in direct proportion to the ambient glucose concentration. A definitive positive correlation has been found between $\mathrm{HbAlc}$ levels and the incidence and progression of diabetic complications. HbAlc levels, therefore, can be used clinically to assess long-term glycemia and to predict risk for development of chronic complications in diabetes. Through the use of an interdisciplinary team approach, focusing on patient education on diabetes management and monitoring blood glucose levels, the test results from SMBG and $\mathrm{HbAlc}$ can be used to achieve target levels. At this time it appears that achieving glycemic control through a comprehensive diabetes care program is cost effective. The goal of the program should be to prevent the long-term complication of diabetes and improve quality of life.

\section{References}

1. American Diabetes Association. Standards of medical care for patients with diabetes mellitus (position statement). Diabetes Care 1994;17: 616-23.

2. Goldstein DE, Little RR, Lorenz RA, et al. Tests of.glycemia in diabetes. Diabetes Care 1995; 18: 896-909.

3. The Diabetes Control and Complication Trial Research Group. The relationship of glycemic exposure (HbAlc) to the risk of development and progression of retinopathy in the Diabetes Control and Complications Trial. Diabetes 1995; 44: 968-83.

4. UK Prospective Diabetes Study (UKPDS) 16: Overview of six years of therapy of a progressive disease. UK Prospective Diabetes Group. Diabetes 1995; 44: $1249-58$

5. Diabetes Control and Complications Trial Research Group. The effect of intensive treatment of diabetes on the development and progression of longterm complications in insulin-dependent diabetes mellitus. N Engl J Med 1993; 329: 977-86.

6. Ohkubo Y., Kishikawa $\mathrm{H}$, Araki E, et al. Intensive insulin therapy prevents the progression of diabetic microvascular complications in Japanese patients with non-insulin dependent diabetes mellitus: a randomized prospective sixyear study. Diabetes Res Clin Pract 1995; 28: 103-17.

7. Klein R, Klein BE, Moss SE, et al. The Wisconsin Epidemiologic Study of Diabetic Retinopathy I1. Prevalence and risk of diabetic retinopathy when age at diagnosis is less than 30 years. Arch Ophthalmol 1984; 102: 520-26.

8. Kususisto J, Mykkanen L, Pyorala K, et al. NIDDM and its metabolic control predict coronary heart disease in elderly subjects. Diabetes 1993; 43: 960-67. 9. Vijan S, Hofer FP, Hayward RA. Estimated benefits of glycemic control in microvascular complications in Type 2 diabetes. Ann Intern Med 1997; 127(9): 788-95.

10. Eastman RC, Javitt JC, Herman WH, et al. Model of complication of NIDDM II. Analysis of health benefits and cost-effectiveness of treating NIDDM with the goal of normoglycemia. Diabetes Care 1997; 20 (5): 735-44. 11. UK Prospective Diabetes Study Group. Intensive blood-glucose control with sulphonylureas or insulin compared with conventional treatment and risk of complications in patients with 2 diabetes (UKPDS 33). Lancet. 1998; 352: 837-53.

12. Klein R, Klein BE, Moss SE, et al. Glycosylated hemoglobin predicts the incidence and progression of diabetic retinopathy. JAMA 1988; 260: 2864-71.
13. Herman WH. Eye disease and nephropathy in NIDDM. Diabetes Care 1990; 13(Suppl 2): 24-29.

14. Nathan DM, Singer DE, Godine JE, et al. Retinopathy in older type It diabetics. Association with glucose control. Diabetes 1986; 35: 797-801.

15. Ballard DJ, Humphrey LL, Melton LJ III. Epidemiology of persistent proteinuria in type II diabetes mellitus: population-based study in Rochester, MN Diabetes 1988; 37: 405-12

16. Humphrey LL, Ballard DJ, Frohnert PP, et al. Chronic renal failure in noninsulin-dependent diabetes mellitus: a population-based study in Rochester, MN. Ann Intern Med 1989; 111: 788-96.

17. Klein R, Klein BEK, Moss S, et al. Proteinuria in diabetes. Arch Intern Med 1988; 148: 181-86.

18. Davidson MB. Diabetic neuropathy. In: Diabetes mellitus: Diagnosis and Treatment, (3rd ed.) New York: Churchill Livingstone, 1991: 314-21.

19. Feldt-Rasmussen B, Mathiesen ER, Deckert T. Effect of two years of strict metabolic control on progression of incipient nephropathy in insulin-dependent diabetes. Lancet 1986; Dec 6: 2 (5819): 1300-04.

20. Kullberg CE, Arnqvist HJ. Good blood glucose control characterizes patients without retinopathy after long diabetes duration. Diabet Med 1995; 12: $314-20$.

21. Chew EY, Mills JL, Metzger BE, et al. Metabolic control and progression of retinopathy. Diabetes in Early Pregnancy Study. Diabetes Care 1995; 18: 631-37. 22. Sameshima $H$, Kai M, Kajiya $S$, et al. Retinopathy and perinatal outcome in diabetic pregnancy [Japanese]. Nippon Sanka Fujinka Gakkai Zasshi 1995; 47: $1048-54$.

23. Heyl W, Schroder W, Kitschke HJ. The course of pregnancy and fetal outcome in diabetic patients with anamnestic fetal death [German]. Z

Geburtshilfe Neonatol 1995; 199: 163-66.

24. Dudl RJ, Biby C, Fordon S. A cost-beneficial control program with glucose self-monitoring. Diabetes Care 1982; 5: 649-50.

25. Fass A, Schellevis EG, Van Eijk JTM. The efficacy of self-monitoring of blood glucose in NIDDM subjects. Diabetes Care 1997; 20: 1482-86.

26. Rutten G, Van Eijk J, Dee Nobel E, et al. Feasibility and effects of a diabetes type 2 protocol with blood glucose self-monitoring in general practice. Fam Pract 1990; 7: 273-78.

27. Kitzmiller JL, Cavin LA, Gin GD, et al. Preconception care of diabetes: glycemic control prevents congenital anomalies. JAMA 1991; 265: 731-36. 28. de Veciana $M$, Major CA, Morgan MA, et al. Postprandial versus preprandial blood glucose monitoring in women with gestational diabetes mellitus requiring insulin therapy. $\mathrm{N}$ Engl J Med 1995; 333: 1237-41.

29. Avignon A, Radauceanu A, Monnier L. Nonfasting plasma glucose is a better marker of diabetic control than fasting plasma glucose in type 2 diabetes. Diabetes Care 1997; 20: 1822-26.

30. Cefalu WT, Prather KL, Murphy WA, et al. Clinical evaluation of serum fructosamine in monitoring elderly outpatient diabetics. J Am Geriatric Society 1989; 37: 833-37.

31. Cefalu WT, Parker TB, Johnson CR. Validity of serum fructosamine as index of short-term glycemic control in diabetic outpatients. Diabetes Care 1988; 11(8): 662-64.

32. Harris MI, Cowie CC, Howie LJ. Self-monitoring of blood glucose by adults with diabetes in the United States population. Diabetes Care 1993; 16: 1116-23. 33. ADA position statement: Tests of glycemia in diabetes. Diabetes Care 1997; 20(Suppl 1): S18-S20.

34. Larsen ML, Horder M, Magensen FE. Effect of long-term monitoring of glycosylated hemoglobin levels in insulin-dependent diabetes mellitus. $\mathrm{N}$ Engl J Med 1990; 323: 1021-25.

35. Gilmer TP, O'Connor PJ, Manning WG, et al. The cost to health plans of poor glycemic control. Diabetes Care 1997; 20: 1847-53.

36. Selby JV, Ray GT, Zhang D, et al. Excess costs of medical care for patients with diabetes in a managed care population. Diabetes Care 1997; 20: 1396-1402.

37. Torrance GW, Feeny D. Utilities and quality-adjusted life years. J Technol Assess Health Care 1989; 5: 559-75.

38. Laupacis A, Feeny D, Detsky AS, Tugwell PX. How attractive does a new technology have to be to warrant adoption and utilization? Tentative guidelines for using clinical and economic evaluations. Can Med Assoc 1992; 146(4): 473-81. 